\title{
Porcionamento dos principais alimentos e preparações consumidos por adultos e idosos residentes no município de São Paulo
}

\author{
Portion sizes of the main foods and preparations \\ consumed by adults and elderly living \\ in the city of São Paulo, Brazil
}

Jackeline Venancio CARLOS'

Silvia ROLIM ${ }^{1}$

Milena Baptista BUENO'

Regina Mara FISBER ${ }^{1}$

\section{R E S U M O}

\section{Objetivo}

Identificar o tamanho das porções dos alimentos e das preparações mais consumidas ou que mais contribuem com o valor energético total da dieta de adultos e idosos.

\section{Métodos}

Realizou-se inquérito domiciliar de base populacional em 2003, com amostra representativa de 1477 indivíduos acima de 20 anos residentes no município de São Paulo. O consumo alimentar foi verificado pelo recordatório de 24 horas, digitado no programa Nutrition Data System. Os alimentos e as preparações selecionados para averiguação da porção foram os consumidos por, no mínimo, $10 \%$ da população de estudo ou que contribuíram com até $80 \%$ do valor energético total. As porções médias, obtidas pelo percentil 50, foram comparadas segundo sexo e estado nutricional, por meio do teste de Kruskal Wallis.

\section{Resultados}

Arroz e feijão foram os alimentos mais consumidos e que mais contribuíram para o valor energético da dieta. Os homens consumiram maior porção destes alimentos, quando são comparados às mulheres. Observou-se que a porção de leite está abaixo do estipulado pelo Guia Alimentar Brasileiro, porém a maior diferença encontrada foi em relação à alface e ao tomate. Verificou-se que indivíduos com excesso de peso consomem maiores porções de peito de frango.

\footnotetext{
1 Universidade de São Paulo, Faculdade de Saúde Pública, Departamento de Nutrição. Av. Dr. Arnaldo, 715, 01246-904, São Paulo, SP, Brasil. Correspondência para/Correspondence to: R.M FISBERG. E-mail: <rfisberg@usp.br>.
} 
384 | J.V. CARLOS et al.

\section{Conclusão}

O tamanho das porções de alguns alimentos é maior entre homens, porém, na prática, não há como diferenciar, em medidas caseiras, valores tão próximos como os encontrados na maioria dos alimentos. As porções dos principais alimentos dos grupos de verduras e legumes e leite e derivados são menores que o proposto pelo Guia Alimentar.

Termos de indexação: Adulto. Hábitos alimentares. Idoso. Inquéritos sobre dietas.

\section{A B S T R A C T}

\section{Objective}

Identify the portion sizes of the most consumed foods and preparations or those that contribute most to the total energy of the diet of adults and seniors.

\section{Methods}

A population-based household survey with a representative sample of 1477 individuals older than 20 years living in the city of São Paulo was done in 2003. Food consumption was investigated with the 24-hour recall and input in the software Nutrition Data System. The foods and preparations whose portions were determined were consumed by at least $10 \%$ of the studied population or represented up to $80 \%$ of the total energy of the diet. The mean portions obtained by the $50^{\text {th }}$ percentile were compared with the Kruskal Wallis test according to gender and nutritional status.

\section{Results}

Rice and beans were the most consumed foods and also contributed most to the total energy of the diet. Men consumed bigger portions of these foods than women. The size of milk portion was below that recommended by the Brazilian Food Guide but the biggest difference regarded the consumption of lettuce and tomato which was way below the recommended amounts. Overweight individuals consume larger portions of chicken breast.

\section{Conclusion}

Men consume larger portions of some foods but in practice it is not possible to differentiate these slightly different amounts for most foods using cooking units. The portion sizes of the main foods of the vegetable and dairy groups are smaller than those recommended by the Food Guide.

Indexing terms: Adult. Food habits. Aged. Diet surveys.

\section{N T R O D U ÇÃ O}

A incidência de obesidade e sobrepeso tem aumentado no Brasil. Alguns aspectos estão relacionados a este aumento além dos fatores genéticos, fisiológicos e metabólicos ${ }^{1}$. Em um Brasil mais urbano e com grandes exigências de cumprimento das jornadas profissionais, as pessoas dispõem de menos tempo para realizar suas refeições. A mesma industrialização que encurtou ou acabou com o horário para o almoço caseiro, trouxe uma nova concepção de gêneros alimentícios. A modernização favoreceu o aumento do comércio de alimentos industrializados e esses produtos, além de serem de fácil acesso, têm seu consumo incentivado pela mídia².
Nas últimas décadas, o tamanho das porções servidas em restaurantes, em estabelecimentos de fast food e até mesmo no domicílio tem aumentado. Young \& Nestlé ${ }^{3}$ mostraram tendência de crescimento das porções americanas desde a década de 70, coincidido com o aumento da incidência da obesidade. A análise temporal sugere que o aumento no tamanho das porções pode ter importância na etiologia da obesidade ${ }^{3}$. Assim, o tamanho das porções tem sido objeto de discussão entre especialistas ${ }^{4}$.

O Nutrition Labeling and Education Act (NLEA) estabelece que o tamanho das porções dos alimentos industrializados deva ser baseado na quantidade habitualmente consumida pela população, expresso, comumente, em medidas 
caseiras 5 . As pessoas tendem a comer em unidades; se Ihes são oferecidos alimentos préporcionados, como cookies, estes, provavelmente, serão consumidos por inteiro ${ }^{6}$. Muitos itens comuns em uma refeição, como sanduíches, hambúrgueres e cheeseburgueres, estão disponíveis como unidades pré-porcionadas. Nos últimos anos o tamanho da porção típica desses itens tem aumentado substancialmente ${ }^{7}$.

Contudo, quando as refeições são feitas dentro ou fora de casa, é possível escolher entre muitos tamanhos de porções. No entanto, embalagens grandes podem conter muitas porções, o que dá ao indivíduo a licença para consumir mais do que somente uma porção ${ }^{8}$.

Informação a respeito da porção média consumida por grupos específicos da população é útil por diversas razões, tais como: elaboração de rótulos nutricionais em embalagens de alimentos, materiais educativos, guias alimentares, avaliação alimentar e aconselhamento nutricional. Além disso, é importante para o desenvolvimento de questionários de freqüência alimentar 9 .

Embora haja inúmeros estudos sobre consumo de alimentos, energia e nutrientes, poucos se referem à quantidade consumida de cada alimento ou preparação ${ }^{3}$. Desta maneira, este estudo tem como objetivo identificar o tamanho das porções mais freqüentemente consumidas e/ou que mais contribuam para o valor energético de adultos e idosos residentes no município de São Paulo.

\section{M É T O D O S}

Trata-se de um estudo de inquérito de saúde domiciliar de base populacional, realizado no município de São Paulo, no ano de 2003. O tamanho da amostra foi calculado por domínio (homens entre 20 e 59 anos, mulheres entre 20 e 59 anos, homens acima de 60 anos e mulheres acima de 60 anos), de forma a obter um mínimo de entrevistas por grupo populacional que possibilitasse estimar uma prevalência de 0,5, com erro de 0,07 considerando um alfa de 0,05 e um efeito de delineamento de 2. Optou-se em duplicar o tamanho da amostra calculada para aumentar o poder dos testes estatísticos, totalizando em 400 indivíduos por domínio. A amostragem foi estratificada por conglomerados em dois estágios: setor censitário e domićlio.

O tamanho da amostra final foi de 1562 indivíduos (743 adultos e 816 idosos). Após a exclusão dos indivíduos que consumiram menos de $500 \mathrm{kcal}$ e mais de $4 \mathrm{mil} / \mathrm{kcal}^{10}$, o total de indivíduos estudado foi de 1 477, sendo 698 adultos e 779 idosos.

O consumo alimentar foi observado pelo método do recordatório de 24 horas (R24h), aplicado por entrevistadores previamente treinados, sendo todos os dias da semana representados. Os recordatórios foram digitados no software Nutrition Data System (NDS), versão 3511. Por se tratar de um programa desenvolvido pela Universidade de Minnesota (EUA) algumas preparações tipicamente brasileiras não constavam e, portanto, foram incluídas utilizando as padronizações de receitas propostas por Fisberg et al. ${ }^{4}$ e Pinheiro et al. ${ }^{12}$. As quantidades das preparações consumidas foram determinadas em medidas caseiras no inquérito e, para a digitação, foram transformadas em gramas ou litros.

A partir dos dados obtidos pelo NDS, fez-se uma listagem dos alimentos que contribuíam com até $80 \%$ do valor energético total, utilizando a fórmula de proporção ponderada de Block et al. ${ }^{13}$. Paralelamente, foi também elaborada uma lista dos alimentos que eram consumidos com maior freqüência e nesta foram incluídos aqueles que apareciam, no mínimo em $10 \%$ da população de estudo. Essa lista foi feita com o intuito de incluir alimentos que não contribuíam com energia, mas que faziam parte da alimentação do paulistano, como por exemplo, os alimentos de origem vegetal. A lista totalizou entre 25 e 31 alimentos nos diferentes domínios e, a partir dessa relação, foram verificadas as porções.

As porções dos alimentos foram classificadas como pequeno, médio e grande, sendo 
considerada como porção média o percentil 50 de consumo, e os demais tamanhos de porção equivalentes aos percentis 25 e 75, respectivamente.

Alguns alimentos, como sal, azeite, vinagre e óleo, foram excluídos das listas devido a uma padronização na digitação dos R24h, segundo a qual se determinou a quantidade a ser digitada quando houvesse o relato: "temperou com sal, azeite e vinagre". Dessa maneira, como as porções desses alimentos podiam não ser fidedignas à porção realmente consumida, podendo estar super ou subestimadas, optou-se por descartá-las do cálculo das porções. Também foi feita a conversão da quantidade de suco em pó para seu correspondente em mililitros $(10,8 \mathrm{~g}$ de pó para $240 \mathrm{~mL}$ de água), a fim de unificar os dois tipos de sucos presentes na lista de freqüência e de estabelecer uma única porção para esse alimento.

A análise dos dados foi realizada com o auxílio do programa estatístico Stata ${ }^{14}$. Quando foi verificada diferença numérica entre as porções, realizou-se o teste de Kruskal Wallis ${ }^{15}$.

O estado nutricional foi avaliado pelo Índice de Massa Corporal (IMC), obtido pela fórmula peso $(\mathrm{kg}) /$ altura $(\mathrm{m})^{2}$ e classificado, segundo a referência da Organização Mundial da Saúde ${ }^{16}$, em: sem excesso de peso (IMC $\leq 25 \mathrm{~kg} / \mathrm{m}^{2}$ para adultos e IMC $\leq 27 \mathrm{~kg} / \mathrm{m}^{2}$ para idosos) e com excesso de peso (IMC $>25 \mathrm{~kg} / \mathrm{m}^{2}$ para adultos e IMC $>27 \mathrm{~kg} / \mathrm{m}^{2}$ para idosos). O peso e a altura foram referidos pelos entrevistados.

O projeto foi aprovado pelo Comitê de Ética da Faculdade de Saúde Pública da Universidade de São Paulo (Protocolo de Pesquisa $\left.n^{\circ} 381\right)$.

\section{RESULTADOS}

As Tabelas 1 e 2 mostram as porções pequena, média e grande de alimentos e preparações consumidos por adultos e idosos, respectivamente. Quanto à freqüência, o arroz foi o alimento mais consumido pelos paulistanos, seguido pelo feijão. Além destes, destacaram-se pão francês, café, bife, leite integral, refrigerante, macarrão, margarina, açúcar, banana, alface e tomate, evidenciando a composição típica da dieta do brasileiro.

Arroz, feijão, macarrão, bife, pão francês e leite também são os principais alimentos que contribuem para o valor energético da dieta. A pizza ocupou lugar de destaque, sendo importante contribuinte energética entre os adultos, sem diferença significante entre as porções médias entre homens e mulheres adultos.

A cerveja e o refrigerante ocuparam posições importantes como contribuintes energéticos. A porção de cerveja para os homens adultos é de, aproximadamente, 2 latas e para as mulheres 2,5 latas.

A comparação por sexo indica que, para alguns alimentos, como arroz, macarrão, açúcar, queijo amarelo, refrigerante, feijão, algumas carnes e banana, os homens adultos consomem porções médias maiores do que as mulheres adultas. Entre os idosos as porções de arroz, feijão, carnes, queijo amarelo, refrigerante, café e hortaliças apresentaram diferença significante.

No grupo das hortaliças destacaram-se como as mais freqüentes a alface, o tomate e a cebola, sem diferença significante quanto às porções entre os adultos. Entre os idosos somente a porção de alface mostrou-se maior para os idosos do sexo masculino $(p<0,05)$.

As frutas, banana, laranja e sucos de frutas (industrializados e naturais) foram freqüentemente consumidas por adultos e idosos. Entre os idosos não houve diferença significativa quanto ao tamanho das porções médias entre os sexos. Para os adultos, a porção de banana é menor para o sexo feminino, em relação à porção de suco industrializado foi observado o contrário. É importante ressaltar que há maior variedade no consumo de frutas pelos idosos, já que maçã e tangerina também aparecem como alimentos mais freqüentemente consumidos por esse grupo. 
Tabela 1. Tamanho das porções (g ou mL) de alimentos consumidos por adultos. São Paulo (SP), 2003.

\begin{tabular}{|c|c|c|c|c|c|c|c|}
\hline \multirow{3}{*}{ Grupo de alimentos } & \multicolumn{6}{|c|}{ Sexo } & \multirow{3}{*}{ Valor de $p$} \\
\hline & \multicolumn{3}{|c|}{ Masculino $(n=329)$} & \multicolumn{3}{|c|}{ Feminino $(n=369)$} & \\
\hline & Pequena & Média & Grande & Pequena & Média & Grande & \\
\hline \multicolumn{8}{|l|}{ Cereais e tubérculos } \\
\hline Arroz & 100,0 & 155,0 & 238,0 & 93,0 & 124,0 & 194,0 & $<0,01$ \\
\hline Macarrão & 124,0 & 260,0 & 320,0 & 67,0 & 131,0 & 256,0 & $<0,01$ \\
\hline Pão francês & 50,0 & 50,0 & 100,0 & 50,0 & 50,0 & 50,0 & - \\
\hline Pão de forma & 30,0 & 50,0 & 75,0 & 25,0 & 50,0 & 50,0 & - \\
\hline Biscoito água e sal & 24,0 & 32,0 & 40,0 & 24,0 & 31,0 & 40,0 & 0,53 \\
\hline Bolo simples & 60,0 & 60,0 & 100,0 & 60,0 & 60,0 & 100,0 & - \\
\hline Batata cozida & 37,5 & 110,0 & 140,0 & 34,0 & 70,0 & 140,0 & 0,49 \\
\hline \multicolumn{8}{|l|}{ Frutas } \\
\hline Banana & 55,9 & 86,0 & 172,0 & 40,0 & 65,0 & 86,0 & 0,04 \\
\hline Suco natural & 123,0 & 212,0 & 313,0 & 84,5 & 247,5 & 256,5 & 0,32 \\
\hline Suco industrial & 240,0 & 240,0 & 350,0 & 178,0 & 244,0 & 244,0 & 0,02 \\
\hline \multicolumn{8}{|l|}{ Leite e derivados } \\
\hline Leite integral & 89,0 & 124,0 & 206,0 & 103,0 & 129,5 & 198,0 & 0,32 \\
\hline Queijo amarelo & 20,0 & 40,0 & 60,0 & 20,0 & 20,0 & 40,0 & 0,02 \\
\hline \multicolumn{8}{|l|}{ Hortaliças } \\
\hline Alface & 20,0 & 30,0 & 50,0 & 20,0 & 30,0 & 50,0 & - \\
\hline Tomate & 30,0 & 55,0 & 91,0 & 30,0 & 45,5 & 60,0 & 0,40 \\
\hline Cebola & 12,0 & 18,0 & 35,0 & 10,0 & 12,0 & 18,0 & 0,10 \\
\hline \multicolumn{8}{|l|}{ Açúcares e doces } \\
\hline Açúcar & 4,0 & 7,2 & 12,0 & 4,0 & 6,0 & 10,0 & 0,02 \\
\hline Refrigerante & 251,5 & 363,5 & 503,0 & 207,5 & 251,5 & 314,5 & $<0,01$ \\
\hline Achocolatado & 25,0 & 25,0 & 37,0 & 17,0 & 25,0 & 25,0 & - \\
\hline \multicolumn{8}{|l|}{ Óleos e gorduras } \\
\hline Margarina/manteiga & 7,5 & 15,0 & 22,5 & 7,50 & 15,0 & 15,0 & - \\
\hline \multicolumn{8}{|l|}{ Leguminosas } \\
\hline Feijão & 86,0 & 100,0 & 172,0 & 52,0 & 86,0 & 86,0 & $<0,01$ \\
\hline \multicolumn{8}{|l|}{ Carnes e ovos } \\
\hline Coxa de frango & 40,0 & 60,0 & 92,4 & 40,0 & 40,0 & 80,0 & 0,06 \\
\hline Peito de frango & 100,0 & 105,0 & 180,0 & 40,0 & 90,0 & 150,0 & 0,01 \\
\hline Lingüiça & 60,0 & 60,0 & 120,0 & 40,0 & 60,0 & 90,0 & - \\
\hline Carne bovina & 100,0 & 105,0 & 160,0 & 75,0 & 100,0 & 112,5 & $<0,01$ \\
\hline Presunto & 30,0 & 30,0 & 45,0 & 15,0 & 30,0 & 30,0 & - \\
\hline \multicolumn{8}{|l|}{ Outros } \\
\hline Café & 67,0 & 82,0 & 128,0 & 60,0 & 90,0 & 120,0 & 0,47 \\
\hline Cerveja & 352,0 & 703,0 & 1205,0 & 351,5 & 874,0 & 1054,5 & 0,80 \\
\hline Chá & 192,0 & 240,0 & 275,0 & 150,0 & 192,0 & 240,0 & 0,04 \\
\hline Pizza & 100,5 & 217,0 & 345,0 & 96,0 & 191,5 & 434,0 & 0,56 \\
\hline
\end{tabular}

Ao avaliar as porções segundo estado nutricional, observou-se que pessoas com excesso de peso consomem porções menores de café (eutróficos: $96 \mathrm{~mL} /$ sobrepeso: $80 \mathrm{~mL}$ ) e maiores de peito de frango (eutróficos: $90 \mathrm{~g} /$ sobrepesos: $112,5 \mathrm{~g}$ ). Somente entre adultos, a porção de leite foi estatisticamente diferente segundo estado nutricional (eutróficos: $150 \mathrm{~mL}$ sobrepeso: $125 \mathrm{~mL}$ ). Entre idosos do sexo masculino a porção de feijão foi estatisticamente maior entre os eutróficos (eutróficos: $86 \mathrm{~g} /$ sobrepesos: 78g). 
388 | J.V. CARLOS et al.

Tabela 2. Tamanho das porções ( $\mathrm{g}$ ou mL) de alimentos consumidas por idosos. São Paulo (SP), 2003.

\begin{tabular}{|c|c|c|c|c|c|c|c|}
\hline \multirow{3}{*}{ Grupo de alimentos } & \multicolumn{6}{|c|}{ Sexo } & \multirow{3}{*}{ Valor de $p$} \\
\hline & \multicolumn{3}{|c|}{ Masculino $(n=379)$} & \multicolumn{3}{|c|}{ Feminino $(n=400)$} & \\
\hline & Pequena & Média & Grande & Pequena & Média & Grande & \\
\hline \multicolumn{8}{|l|}{ Cereais } \\
\hline Arroz & 100,0 & 132,0 & 212,0 & 75,0 & 100,0 & 150,0 & $<0,01$ \\
\hline Macarrão & 88,0 & 170,0 & 288,0 & 85,0 & 180,0 & 264,0 & 0,78 \\
\hline Pão francês & 50,0 & 50,0 & 50,0 & 50,0 & 50,0 & 50,0 & - \\
\hline Batata cozida & 51,0 & 70,0 & 140,0 & 30,0 & 60,0 & 140,0 & 0,07 \\
\hline Pão de forma & 25,0 & 50,0 & 50,0 & 25,0 & 50,0 & 50,0 & - \\
\hline Biscoito água e sal & 24,0 & 32,0 & 40,0 & 24,0 & 32,0 & 32,0 & - \\
\hline \multicolumn{8}{|l|}{ Frutas } \\
\hline Banana & 52,0 & 86,0 & 86,0 & 40,0 & 86,0 & 86,0 & - \\
\hline Laranja & 180,0 & 180,0 & 360,0 & 131,0 & 180,0 & 180,0 & - \\
\hline Suco natural & 178,0 & 151,0 & 252,0 & 89,0 & 84,0 & 251,0 & 0,35 \\
\hline Suco industrial & 144,0 & 240,0 & 240,0 & 200,0 & 244,0 & 244,0 & $<0,01$ \\
\hline Maçã & 65,0 & 120,0 & 130,0 & 120,0 & 120,0 & 130,0 & - \\
\hline Tangerina & 135,0 & 140,0 & 180,0 & 137,5 & 140,0 & 140,0 & - \\
\hline \multicolumn{8}{|l|}{ Leite e derivados } \\
\hline Leite & 99,0 & 132,0 & 198,0 & 99,0 & 132,0 & 198,0 & - \\
\hline Queijo amarelo & 20,0 & 40,0 & 40,0 & 20,0 & 20,0 & 30,0 & $<0,01$ \\
\hline Queijo branco & 30,0 & 30,0 & 40,0 & 30,0 & 32,5 & 60,0 & 0,15 \\
\hline \multicolumn{8}{|l|}{ Hortaliças } \\
\hline Alface & 20,0 & 30,0 & 50,0 & 20,0 & 24,0 & 40,0 & 0,01 \\
\hline Tomate & 27,3 & 45,5 & 91,0 & 27,5 & 45,0 & 54,5 & 0,05 \\
\hline Cebola & 11,0 & 12,0 & 20,0 & 10,0 & 12,0 & 24,0 & - \\
\hline Cenoura & 24,0 & 25,0 & 56,0 & 10,0 & 22,0 & 48,0 & 0,01 \\
\hline \multicolumn{8}{|l|}{ Açúcares e doces } \\
\hline Açúcar & 4,0 & 6,0 & 12,0 & 4,0 & 6,3 & 12,0 & 0,94 \\
\hline Refrigerante & 151,0 & 249,0 & 251,5 & 137,5 & 207,5 & 249,0 & $<0,01$ \\
\hline \multicolumn{8}{|l|}{ Óleos e gorduras } \\
\hline Margarina/manteiga & 7,5 & 7,5 & 15,0 & 7,5 & 7,5 & 15,0 & - \\
\hline \multicolumn{8}{|l|}{ Leguminosas } \\
\hline Feijão & 54,5 & 86,0 & 107,5 & 43,0 & 78,6 & 86,0 & $<0,01$ \\
\hline \multicolumn{8}{|l|}{ Carnes e ovos } \\
\hline Lingüiça & 36,0 & 60,0 & 60,0 & 60,0 & 60,0 & 120,0 & - \\
\hline Peito de frango & 100,0 & 140,0 & 209,0 & 56,0 & 100,0 & 170,0 & 0,02 \\
\hline Coxa de frango & 38,5 & 61,5 & 92,5 & 31,0 & 31,0 & 65,0 & $<0,01$ \\
\hline Carne bovina & 70,0 & 95,0 & 120,0 & 75,0 & 95,0 & 100,0 & - \\
\hline \multicolumn{8}{|l|}{ Outros } \\
\hline Café & 50,0 & 84,5 & 125,0 & 50,0 & 80,0 & 120,0 & 0,01 \\
\hline Pizza & 53,0 & 96,0 & 199,5 & 96,0 & 192,0 & 434,0 & 0,30 \\
\hline Sopa & 76,0 & 152,0 & 227,5 & 76,0 & 152,0 & 184,0 & - \\
\hline Chá & 144,0 & 192,0 & 240,0 & 150,0 & 192,0 & 240,0 & - \\
\hline
\end{tabular}

DIS CUSS Ã O

As porções encontradas para alguns alimentos no presente estudo apresentaram valores de percentis 25,50 e 75 próximo, e, algumas vezes iguais, mostrando que a distribuição do consumo na população estudada não possui distribuição normal. Isto dificultou a diferenciação precisa das porções, já que, na prática, não há como diferenciar, em medidas 
caseiras, valores tão próximos como os encontrados.

A comparação das porções segundo o sexo mostra que, na maioria das vezes, não há distinção do tamanho da porção. Entre os homens a necessidade de energia é, realmente, maior e, portanto a porção de alguns alimentos fornecedores de energia, como macarrão, queijo, banana, feijão e refrigerante, foi estatisticamente maior.

A escassez de estudos a respeito das porções consumidas pelos brasileiros, bem como pelos paulistanos, impede de comparar o consumo atual com alguma referência passada, no entanto pode-se usar o Guia Alimentar para a População Brasileira ${ }^{17}$, com o intuito de avaliar se a porção consumida está próxima ao proposto.

A definição de porção adotada pelo Guia Alimentar é "a quantidade de alimento em sua forma usual de consumo expressa em medidas caseiras, unidade ou forma de consumo, considerando também a quantidade média do alimento que deve ser usualmente consumida por pessoas sadias, para compor uma alimentação saudável". Desta forma, porção não é definida como a quantidade realmente consumida pela população, que, geralmente, tem dificuldade de entender qual o tamanho da porção recomendada pelos guias alimentares, freqüentemente utilizados em serviços de saúde para ações educativas de promoção da saúde.

A maior parte das porções dos alimentos analisados é semelhante ao proposto pelo referido guia alimentar. Os que mais se diferenciaram foram, por ordem crescente, alface, açúcar refinado, batata cozida, tomate, macarrão, suco de frutas e leite.

Entre as porções de alimentos mais consumidos e/ou que fornecem mais energia do grupo de cereais e tubérculos destacaram-se o macarrão e a batata. A porção de macarrão no presente estudo foi, aproximadamente, $40 \%$ superior ao do Guia. Já a porção de batata realmente consumida pela população chegou a ser até $65 \%$ menor que a do Guia. A porção de batata proposta pelo Guia Alimentar é de uma unidade e meia, porém observou-se que a porção realmente consumida é de meia batata entre mulheres adultas e entre idosos de ambos os sexos.

O tamanho da porção média de alimentos do grupo de leite e derivados observado no presente estudo foi, aproximadamente, 30\% menor que o proposto. Em medidas caseiras, a quantidade de leite consumida por esta população equivale a três quartos de uma xícara de chá. A porção de queijo, outro importante alimento neste grupo, foi $50 \%$ menor somente entre mulheres. Este é um importante grupo de alimentos fonte de cálcio, se a porção é menor do que a esperada, provavelmente a necessidade de cálcio não está sendo suprida com a recomendação de 3 porções ao dia.

A variedade de consumo de frutas é maior entre os idosos, pois neste grupo houve o acréscimo da maçã e da tangerina entre os mais consumidos. A porção de banana é igual para homens adultos e idosos de ambos os sexos, correspondente a uma unidade de banana nanica. A porção deste alimento para as mulheres adultas corresponde a uma banana do tipo maçã. O tamanho das porções dos alimentos analisados deste grupo foi semelhante ao do Guia, devido ao fato de o consumo e a recomendação serem em unidades inteiras. Porém, quando a fruta foi consumida na forma de suco, observou-se que a porção do adulto (média de $230 \mathrm{~mL}$ ) é superior à do idoso (média de $120 \mathrm{~mL}$ ) e à da proposta pelo Guia (média de 160mL).

Na comparação com a porção proposta pelo Guia, o alimento que mais se diferenciou foi a alface. A proposta é de 15 folhas (120g) enquanto que a quantidade realmente consumida é de 3 a 4 folhas (30g). O tomate também teve uma diferença grande, no presente estudo a porção consumida foi de, aproximadamente, 2 fatias enquanto que o proposto são 4 fatias.

Schwartz \& Byrd-Bredbenner ${ }^{18}$ observaram que, entre jovens adultos, as porções consumidas 
de verduras e legumes são $25 \%$ menores do que a porção referência. Por outro lado, a porção de leite consumida por jovens americanos é próxima do recomendado, ao contrário dos resultados deste estudo.

A porção de açúcar refinado, alimento analisado neste estudo, quando utilizada para adoçar bebidas ou outros alimentos e não como ingrediente de preparações, foi de 4 a 7 gramas, correspondente a menos de $25 \%$ da porção contida no Guia. Ressalta-se que quando o individuo não conseguia relatar a quantidade de açúcar utilizado, foi estipulada uma porção padrão, que correspondia a $5 \%$ da quantidade da bebida.

Notou-se que bebidas como refrigerante e cerveja são importantes fontes de energia. Ressalta-se que o consumo de cerveja pelas muIheres adultas não é tão freqüente quanto pelos homens, no entanto a porção média foi maior para este grupo, porém sem significância estatística.

Com o contínuo aumento das taxas de obesidade, é importante entender como o tamanho das porções dos alimentos pode influenciar a ingestão de energia e o ganho de peso ${ }^{19}$. Como o tamanho da porção é um fator relacionado ao meio em que o indivíduo se insere, deve ser avaliado com atenção para tratamento e prevenção da obesidade ${ }^{20}$, fornecendo alimentos em porções que satisfaçam os consumidores em relação à quantidade e à qualidade, a um preço acessível21.

As porções dos principais alimentos consumidos dos grupos de verduras e legumes e leite e derivados são menores que o proposto pelo Guia Alimentar. Além disso, alimentos pobres em valor nutritivo, mas com alto valor energético têm participação importante na alimentação do paulistano e o tamanho da porção é grande. Por esse motivo pesquisas na área de consumo alimentar e, em especial, sobre o tamanho de porções consumidas devem ser feitas, para entender a contribuição do tamanho das porções e o desenvolvimento da obesidade. E, para melhorar a eficácia de um programa de alimentação que pretende modificar hábitos alimentares, este deve ser adaptado ao consumo real da população brasileira.

Profissionais da área da saúde podem usar os resultados do presente estudo para aperfeiçoamento de guias alimentares e manuais fotográficos, com o intuito de viabilizar a avaliação do consumo alimentar, além de colaborar com novos estudos para determinar uma possível tendência em relação ao tamanho das porções.

\section{COLABORADORES}

J.V. CARLOS e S. ROLIM, responsáveis pela tabulação, organização, análise dos dados e pela redação do artigo; M.B. BUENO responsável pela orientação da análise estatística e pela redação do artigo; R.M. FISBER responsável pela orientação dos alunos e pela execução do projeto.

\section{REFERÊ NCIAS}

1. Oliveira $C L$, Fisberg $M$. Obesidade na infância e adolescência: uma verdadeira epidemia. Arq Bras Endocrinol Metab. 2003; 47(2):107-8.

2. Monteiro CA, Mondini L, Souza ALM, Popkin BM. Da desnutrição para a obesidade: a transição nutricional no Brasil. In: Monteiro CA, organizador. Velhos e novos males da saúde no Brasil: a evolução do país e de suas doenças. São Paulo: Hucitec; 1995. p.79-89.

3. Young LR, Nestle M. Expanding portion sizes in the US marketplace: implications for nutrition counseling. J Am Diet Assoc. 2003; 103(2):231-4.

4. Fisberg RM, Slater Villar B, Colucci ACA, Philippi ST. Alimentação equilibrada na promoção da saúde. In: Cuppari L. Nutrição clínica no adulto. São Paulo: Manole; 2002. p.47-54. Guias de medicina ambulatorial e hospitalar.

5. Nutrition education and labeling act of 1990, Pub L. no 101-535, 104 Stat. 2353 (1990 Nov 8).

6. Siegel PS. The completion compulsion in human eating. Psychol Rep. 1957; 3:15-6.

7. Nielsen SJ, Popkin BM. Patterns and trends in food portion sizes, 1977-1998. JAMA. 2003; 289(4): 450-3

8. Antonuk B, Block $L$. The effect of single serving versus entire package nutritional information on 
consumption norms and actual consumption of a snack food. J Nutr Educ Behav. 2006; 38(6): 365-70.

9. Smiciklas-Wright H, Mitchell DC, Mickle SJ, Goldman JD, Cook A. Foods commonly eaten in the United States, 1989-1991 and 1994-1996: are portion sizes changing? J Am Diet Assoc. 2003; 103(1):41-7.

10. Willett WC. Nutritional epidemiology. 2nd ed. New York: Oxford University Press; 1998.

11. Nutrition Coordinating Center. Food and Nutrient Database. [computer program]. Version 2005. Minnesota: NCC, 2005.

12. Pinheiro ABV, Lacerda EMA, Benzecry EH, Gomes MCS, Costa VM. Tabela para avaliação de consumo alimentar em medidas caseiras. 4a. ed. São Paulo: Atheneu; 2000.

13. Block G, Hartman AM, Dresser CM, Carroll MD, Gannon J, Gardner L. A data-based approach to diet questionnaire design and testing. Am J Epidemiol. 1986; 124(3): 453-69.

14. Stata Corporation. Intercooled Stata. [computer program]. Version 8.0. Texas: College Station, 2003.

15. Dawson B, Trapp RG. Basic \& clinical biostatistic. 3rd ed. New York: McGraw-Hill; 2001.
16. World Health Organization. Joint WHO/FAO Expert Conculation on Diet, Nutrition and the prevention of crhonic diseases. Diet, nutrition and the prevention of chronic diseases. Geneva; 2003. WHO Technical Report Series 916.

17. Brasil. Ministério da Saúde. Guia alimentar para a população brasileira: promovendo a alimentação saudável. [cited 200514 Oct]. Avaiable from: <http://www.saude.gov.br/alimentação>.

18. Schwartz J, Byrd-Bredbenner C. Portion distortion: typical portions sizes selected by young adults. J Am Diet Assoc. 2006; 106(9):1412-8.

19. Ello-Martin JA, Ledikwe JH, Rolls BJ. The influence of food portion size and energy density on energy intake: implications for weight management. Am J Clin Nutr. 2005; 82(Suppl):236-41.

20. Rolls BJ, Morris EL, Roe LS. Portion size of food affects energy intake in normal-weight and overweight men and women. Am J Clin Nutr. 2002; 76(6):1207-13

21. Ledikwe JH, Ello-Martin JA, Rolls BJ. Portion sizes and the obesity epidemic. J Nutr. 2005; 135(4): 905-9. 